\title{
Role of polar extracts from two quinoa varieties in prevention of steatohepatitis and cardiovascular diseases and improving glucose tolerance in rats
}

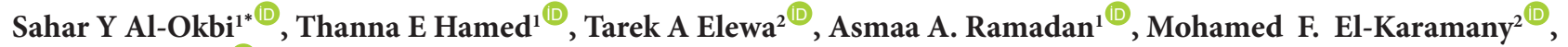 \\ Bakry A. Bakry² ${ }^{\mathbb{D}}$ \\ ${ }^{1}$ Nutrition and Food Sciences Department, National Research Centre, Dokki, Cairo, Egypt \\ ${ }^{2}$ Field Crops Research Department, Agriculture and Biological division, National Research Centre, Dokki, Cairo, Egypt
}

\section{A R T I C L E I N F O}

Article Type:

Original Article

Article History:

Received: 28 January 2020

Accepted: 10 April 2020

Keywords:

Quinoa

Phenolic compounds

Fatty liver

Lipid profile

Oxidative stress

Glucose tolerance

\begin{abstract}
A B S T R A C T
Introduction: Steatohepatitis, which is the deposition of fat in the liver with inflammation and starting of necrosis, can induce cardiovascular diseases (CVDs). The aim of this research was to study the preventive effects of steatohepatitis and CVD by ethanol extract of two quinoa varieties (quinoa 1 and hualhuas) in rats.

Methods: Phenolic and flavonoid compounds were determined in the extracts utilizing colorimetric and high-performance liquid chromatography techniques. The 2,2-diphenyl-1picryl-hydrazil (DPPH) scavenging activity was assessed for the extracts. Rats were divided into four groups, the first group was fed on a balanced diet (negative control), and other groups consumed a high fructose-fat diet (HFFD) to induce steatohepatitis and CVD. The second group served as a positive control; however, the third and fourth groups were treated by ethanol extract of quinoa 1 and hualhuas, respectively. Different biochemical changes, as well as liver and heart histopathology, were followed.

Results: Results showed significant elevation in liver lipids, plasma malondialdehyde, total cholesterol (T-C), triglycerides and low-density lipoprotein cholesterol with reduction of highdensity lipoprotein cholesterol (HDL-C) and total antioxidant as well as a significant increase in T-C/HDL-C in control positive group $(P<0.05)$ compared to control negative group. Plasma parameters and liver lipids were improved by the extracts; hualhuas was superior concerning the effect on lipid while quinoa 1 was more efficient in reducing oxidative stress. Oral glucose tolerance curve and the histopathology of the liver and heart tissues were improved by both extracts. Total phenolic and DPPH scavenging activity were higher in quinoa 1 than hualhuas. Protocatechuic and rutin were the major identified phenolic acid and flavonoid compounds, respectively in the extracts.

Conclusion: Quinoa extracts are able to prevent the progression of steatohepatitis and CVD, and might be beneficial in patients with such diseases.
\end{abstract}

Implication for health policy/practice/research/medical education:

This research showed that the ethanol extracts of two quinoa varieties were able to prevent the progression of fatty liver to steatohepatitis and guarded against development of CVD with variable degrees. Hence, they might be beneficial in patients suffering from these diseases.

Please cite this paper as: Al-Okbi SY, Hamed TE, Elewa TE, Ramadan AA, El-Karamany MF, Bakry BA. Role of polar extracts from two quinoa varieties in prevention of steatohepatitis and cardiovascular diseases and improving glucose tolerance in rats. J Herbmed Pharmacol. 2021;10(1):93-101. doi: 10.34172/jhp.2021.09.

\section{Introduction}

The pseudo cereal Chenopodium quinoa known as quinoa originally grows in Bolivia, Peru, Colombia, and nearby countries. Being a potential nutritious plant, $C$. quinoa has been cultivated in Africa, Asia, Europe and
North America (1). Quinoa has high nutritional value, so it is well accepted as alternative food, especially in developing countries. In addition to its role in supplying different nutrients and nutritional function; quinoa was reported as rich source of phenolic and flavonoids with 
health promoting effect (2-5). Quinoa was proposed to possess nutraceutical activity due to the presence of such bioactive constituents (2). Phenolic compounds possess antioxidant, anti-inflammatory, and anti-diabetic effects, thereby might prevent different chronic diseases $(4,6,7)$.

Steatohepatitis, which is the accumulation of fat in the liver accompanied by inflammation and some sorts of necrosis, is now accused as one of the major risks of CVD $(8,9)$, which is considered as the main cause of mortality worldwide. So management of such conditions is considered a priority for medical professionals.

The reported bioactive constituents, along with the anti-inflammatory and antioxidant effect of quinoa potentiated the research team to study the potential health benefits of the polar quinoa extract represented by ethanol extracts. Therefore, the current research aimed to assess different bioactive constituents of the ethanol extracts of two quinoa varieties. The aim included studying the invitro antioxidant and the biological activity of such polar extracts in the rat model of CVD and steatohepatitis.

\section{Materials and Methods}

Plant materials

Two varieties from the seeds of Chenopodium quinoa Willd., family Amaranthaceae were studied in the present work:

Variety 1 (V1): Quinoa 1 was obtained from Agricultural Research Centre, Giza, Egypt.

Variety 2 (V2): Hualhuas was obtained from International Potato Center (CIP), Lima, Peru.

Preparation of ethanol extracts of the two varieties of Chenopodium quinoa

The seeds from the two varieties were washed separately with tap water and dried in a hot air oven at $40^{\circ} \mathrm{C}$. A known weight from seeds of each variety was placed in a soxhlet apparatus and subjected to continuous extraction by petroleum ether $\left(40-60^{\circ} \mathrm{C}\right)$ followed by ethanol. The ethanol was evaporated from the ethanol extract under reduced pressure by rotary evaporator at a temperature not exceeding $40^{\circ} \mathrm{C}$.

Determination of total phenolic content of the alcohol extract of the two varieties

Total phenolics were determined calorimetrically in the extracted samples using Folin-Ciocalteu reagent (10). The reaction mixture contained $200 \mu \mathrm{L}$ of the extracted sample, $1000 \mu \mathrm{L}$ of freshly prepared diluted Folin-Ciocalteu reagent and $800 \mu \mathrm{L}$ of sodium carbonate solution (7.5\%). Mixtures were mixed and kept in the dark at room temperature for 30 minutes to complete the reaction. Absorbance was measured at $765 \mathrm{~nm}$ using UVPC spectrophotometer. Gallic acid was used as a standard and the results were calculated as mg gallic acid equivalent (GAE) per g of dry sample. The samples were determined in triplicate.
Determination of phenolic acid and flavonoid compounds in the ethanol extract of the two varieties

Phenolic compounds were extracted and determined, as previously reported (11). Briefly, $1 \mathrm{~g}$ of each sample was placed in quick fit conical flask, and $20 \mathrm{~mL}$ of $2 \mathrm{M}$ sodium hydroxide was added. Then, the flasks were flushed with N2, and the stoppers were placed. After shaking the flasks for 4 hours at room temperature, the $\mathrm{pH}$ was adjusted to 2 with $6 \mathrm{M}$ hydrochloric acid. The content of each flask was centrifuged at $5000 \mathrm{rpm}$ for 10 minutes and the supernatant was collected. Phenolic compounds were extracted twice with $50 \mathrm{~mL}$ ethyl ether and ethyl acetate (1:1). The organic phase was separated, and the solvent was evaporated at $45^{\circ} \mathrm{C}$. Then, the residues were re-dissolved in $2 \mathrm{~mL}$ methanol and analyzed by highperformance liquid chromatography (HPLC).

\section{HPLC conditions}

Agilent Technology 1100 series liquid chromatograph equipped by an auto-sampler and a diode-array detector was used. Eclipse XDB-C18 (150 X $4.6 \mu \mathrm{m}, 5 \mu \mathrm{m})$ with the C18 guard column (Phenomenex, Torrance, CA) was run. Acetonitrile (solvent $\mathrm{A}$ ) and $2 \%$ acetic acid in water (solvent B) were used as mobile phase. The flow rate was $0.8 \mathrm{~mL} / \mathrm{min}$ for a total run time of 70 minutes, and the gradient program was $100 \% \mathrm{~B}$ to $85 \% \mathrm{~B}$ in 30 minutes, $85 \%$ B to $50 \%$ B in 20 minutes, $50 \%$ B to $0 \%$ B in 5 minutes and $0 \% \mathrm{~B}$ to $100 \% \mathrm{~B}$ in 5 minutes. Samples were filtered through a $0.45 \mu \mathrm{m}$ Acrodisc syringe filter (Gelman Laboratory, MI) before injection. Phenolic acids and flavonoids were identified and calibrated by comparison with standards.

DPPH radical scavenging activity of the alcohol extracts of the two varieties

Free radical scavenging capacity of the alcohol extracts of V1 and 2 were determined using in-vitro assay; the stable $\mathrm{DPPH}^{*}$ radical (2,2-diphenyl-1-picryl-hydrazil) (12). The final concentration was $200 \mu \mathrm{M}$ for $\mathrm{DPPH}^{*}$, and the final reaction volume was $3.0 \mathrm{~mL}$. The absorbance was measured by a spectrophotometer at $517 \mathrm{~nm}$ against a blank of pure methanol after 60 minutes of incubation in a dark condition. A standard curve was prepared using Trolox. Results were expressed as mg Trolox equivalents (TE)/g sample. Additionally, DPPH percentage inhibition was calculated according to the following equation:

$$
\text { DPPH scavenging } \left.(\%)=\left[\left(A_{0}-A_{1}\right) / A_{0}\right) X 100\right]
$$

Where $\mathrm{A}_{0}$ was the absorbance of the control reaction and $A_{1}$ was the absorbance in the presence of the extract (13).

Animal experiments

Animals

Male Sprague Dawley rats of 70-85 g body weight were 
used in the present study. The animals were obtained from the Animal House of National Research Centre, Cairo, Egypt. Animals were kept individually in stainless steel cages; water and food were given ad-labium with 12 hours light/dark cycle.

\section{Diets}

Two experimental diets were prepared, as in Table 1; a balanced and a high fructose-high fat diet. The high fructose-high fat food was prepared as previously reported (14) with some modification to induce CVD and steatohepatitis (as components of metabolic syndrome).

\section{Experimental procedure}

Twenty-four rats were divided into 4 groups, each of six rats. The first was normal group where the rats received a balanced diet. The second group was CVD and steatohepatitis (CS) control where the rats were fed on high fructose-fat diet (HFFD). Groups three and four were fed on HFFD and given daily oral dose of $500 \mathrm{mg} /$ $\mathrm{kg}$ rat body weight from ethanol extract of V1 and V2, respectively. During the experiment, body weight and food intake were recorded weekly. For performing oral glucose tolerance test (OGTT), after a month; the rats of all groups fasted overnight and in the morning of the next day a drop of blood was taken from all rats' tails to assess blood glucose at zero time (fasting blood sugar) using glucose strips and their corresponding glucometer. The two tested extracts doses were given orally to rats of groups 3 and 4, then all rats, including the two control groups, were given $1 \mathrm{~g}$ glucose $/ \mathrm{kg}$ rat body weight in solution form (15). The glucose was purchased from $\mathrm{BDH}$, England. Blood glucose was re-determined after 1/2, 1, 2, and 4 hours from glucose intake. After performing OGTT, the rats returned to their original diet and doses style of the biological experiment. At the end of the experiment (5 days later from performing OGTT), total food intake, body-weight gain, and food efficiency ratio (Body-weight gain/total food intake) were calculated. After an overnight fast, blood samples were collected from anaesthetized rats in heparinized tubes, and the plasma was separated by centrifugation at $3000 \mathrm{rpm}$ for 15 minutes. Plasma total cholesterol (T-C) (16), high-density lipoprotein

Table 1. Composition of the animal diets $(\mathrm{g} / 100 \mathrm{~g})$

\begin{tabular}{lcc}
\hline \multirow{2}{*}{ Ingredients } & \multicolumn{2}{c}{ Type of diet } \\
\cline { 2 - 3 } & Balanced diet & High fructose-high fat diet \\
\hline Casein & 12 & 12 \\
Sunflower oil & 10 & - \\
Starch & 68.5 & - \\
Sheep tallow & - & 20 \\
Fructose & - & 63.5 \\
Cellulose & 5 & - \\
Mineral mixture & 3.5 & 3.5 \\
Vitamin mixture & 1 & 1 \\
\hline
\end{tabular}

cholesterol (HDL-C) (17), and triglycerides (TGs) (18) were determined. The T-C/HDL-Ch and low-density lipoprotein cholesterol (LDL-C) were calculated (19). Plasma malondialdehyde (MDA) was determined as an indicator of lipid peroxidation (20) while total antioxidant capacity which reflects the antioxidant status was assessed as previously reported (21). Rats were dissected, and livers were immediately separated; a part was stored at $-20^{\circ} \mathrm{C}$ till analyzed. Total hepatic lipids were extracted and weighed $(22,23)$. Another part of each liver was kept with the heart in $10 \%$ formalin for histopathological examinations (24). Tissue specimens of liver and heart were fixed in $10 \%$ formalin, prepared and stained for light microscopy. For dehydration, serial dilutions of alcohol were used with subsequent clearance in xylene. Then the specimens were embedded in paraffin wax in a hot air oven at $56^{\circ} \mathrm{C}$ for 6 hours. Paraffin wax tissue blocks were sectioned by using microtome at 5-6 microns thickness. Then, sections were collected on glass slides and deparaffinized. They were stained for routine histopathological examination using Hematoxylin and Eosin stain (H\&E).

Statistical analysis

The results of the animal experiments and total phenolics were expressed as the mean \pm standard error (SE). Data from animal experiments were analyzed statistically using the one-way analysis of variance ANOVA followed by Tukey test using the SPSS statistical program. In all cases, $P<0.05$ was used as the criterion of statistical significance.

\section{Results}

DPPH scavenging activity and total phenolic content of the extracts

Total phenolic content and DPPH scavenging activity of ethanol extracts of both quinoa varieties are shown in Table 2. The total phenolic content in V1 $(6.761 \pm 0.42$ $\mathrm{mg}$ GAE/g) was higher than that in V2 $(5.435 \pm 0.31 \mathrm{mg}$ GAE/g). The DPPH scavenging activity of V1 (16.008 mg $\mathrm{TE} / \mathrm{g}$ extract and $58.18 \% \mathrm{DPPH}$ inhibition) was higher than that of V2 (10.838 $\mathrm{mg} \mathrm{TE} / \mathrm{g}$ and $43.18 \% \mathrm{DPPH}$ inhibition).

Phenolic and flavonoids profiles of ethanol extract of quinoa

Phenolic and flavonoids profiles of ethanol extracts of both quinoa varieties are compiled in Table 3. Twelve compounds were identified in both V1 and V2. The major compound in both quinoa variety identified by HPLC was protocatechuic (208.176 and $45.056 \mu \mathrm{g} / \mathrm{g}$ in V1 and $\mathrm{V} 2$, respectively). The second predominant compound in V1 was $p$-hydroxybenzoic, followed by ferulic, cinnamic, rutin, lutiolin, sinapic, chlorogenic acid, and $p$-coumaric (72.052, 44.405, 34.881, 32.391, 16.986, 16.660, 15.654 and $12.078 \mu \mathrm{g} / \mathrm{g}$, respectively). In V1; syringic, kaempferol and chrysin were present as $8.428,7.161$, and $6.965 \mu \mathrm{g} / \mathrm{g}$, respectively. The detected compounds in V2 other than 
Table 2. Total phenolic content and DDPH scavenging activity of alcohol extracts of both quinoa varieties

\begin{tabular}{lcc}
\hline \multirow{2}{*}{ Parameters } & \multicolumn{2}{c}{ Quinoa } \\
\cline { 2 - 3 } & V1 & V2 \\
\hline Total phenolic (mg GAE/g) & $6.761 \pm 0.42$ & $5.435 \pm 0.31$ \\
DPPH scavenging activity & & \\
DPPH (mg TE/g) & 16.008 & 10.838 \\
Percentage inhibition of DPPH & 58.18 & 43.18 \\
\hline
\end{tabular}

DPPH: 2,2-diphenyl-1-picryl-hydrazil, TE: trolox equivalent, GAE: gallic acid equivalent.

Table 3. Phenolic and flavonoids profile $(\mu \mathrm{g} / \mathrm{g})$ of alcohol extract of both quinoa varieties

\begin{tabular}{|c|c|c|}
\hline Compound & Quinoa V1 & Quinoa V2 \\
\hline Gallic & ND & ND \\
\hline Protocatechuic & 208.176 & 45.056 \\
\hline$p$-Hydroxybenzoic & 72.052 & 16.367 \\
\hline Gentisic & ND & ND \\
\hline Catechin & ND & ND \\
\hline Chlorogenic & 15.654 & 11.971 \\
\hline Caffeic & ND & ND \\
\hline Syringic & 8.428 & 9.035 \\
\hline Vanillic & ND & ND \\
\hline Ferulic & 44.405 & 21.186 \\
\hline Sinapic & 16.660 & 9.387 \\
\hline$p$-Coumaric & 12.078 & 17.697 \\
\hline Rutin & 32.391 & 12.134 \\
\hline Apigenin-7-glucoside & ND & ND \\
\hline Rosmarinic & ND & ND \\
\hline Cinnamic & 34.881 & 22.509 \\
\hline Lutiolin & 16.986 & 2.200 \\
\hline Kaempferol & 7.161 & 1.475 \\
\hline Chrysin & 6.965 & 10.900 \\
\hline
\end{tabular}

protocatechuic when arranged in descending order according to the concentration were cinnamic, ferulic, p-coumaric, $p$-hydroxybenzoic, rutin, chlorogenic, chrysin, sinapic, and syringic within the range 22.509 to $9.035 \mu \mathrm{g} / \mathrm{g}$. Lutiolin and kaempferol showed the least levels in V2 (2.200 and1.475 $\mu \mathrm{g} / \mathrm{g}$, respectively).

\section{Results of the biological experiment}

Glucose tolerance of different groups represented by fasting blood glucose and blood glucose after 1/2, 1, 2 and 4 hours from oral glucose administration (Oral glucose tolerance) are present in Table 4. The fasting blood glucose showed no significant changes when all groups were compared to normal control. Blood glucose of CS control after $1 / 2$, 1,2 , and 4 hours from oral glucose administration were significantly higher than that of control normal. The test groups treated by the extracts showed significant reduction of blood glucose in the different time intervals compared to CS control. All blood glucose levels on the different time intervals of the groups treated by the extracts matched that of the control normal except for that after 4 hours on administration of V2 extract.

Table 5, demonstrates the lipid profile of the different experimental groups. CS control showed significant increase in TG, T-C, LDL-C, and T-C/HDL-C with concomitant decrease in high density lipoprotein cholesterol when compared to normal control. Treatment of CS rats with the extracts of the two varieties of quinoa produced significant improvement in all lipid parameters compared to CS control except for HDL-C on treatment with the ethanol extract of V1. It could be noticed that control group that fed on high fructose and saturated fat showed significant elevation in MDA and liver fat with consequent reduction in total antioxidant capacity (TAC) compared to control normal group. Tested extracts produced significant reduction in MDA compared to CS control. Total antioxidant capacity was only significantly improved on treatment with ethanol extract of quinoa variety 1compared to CS control. Total liver fat was significantly reduced on both treatments compared to CS control.

Nutritional parameters of different experimental groups are shown in Table 6. The results demonstrated no significant changes in final body weight, body weight gain, total food intake, and food efficiency ratio in CS control compared to normal control. Treatment with the extracts of either V1 or V2 produced a significant reduction in body weight gain, total food intake, and food efficiency ratio compared to either CS or normal control group.

\section{Histopathological changes}

Histopathological changes are shown in Figures 1 and 2 as well as Tables 7 and 8 . Concerning hepatic changes, the normal control group showed that the main architecture of the hepatic tissue was within normal appearance (Figure 1A). Hepatic tissue of the control group with steatohepatitis demonstrated degeneration and vacuolation of hepatic cytoplasm, with fatty changes and large fat globules. The hepatic sinusoidal spaces were distorted. Other group of cells showed necrobiosis, pyknotic nucleus, and homogenous eosinophilic cytoplasm with activation of Kupffer phagocytic cells associated with infiltration of mononuclear inflammatory cells (Figure 1B). Hepatic tissue of the group given ethanol extract of V1 showed deep eosinophilic cytoplasm and mild infiltration of mononuclear inflammatory cells with degeneration and vacuolation of the hepatic cytoplasm, mild fatty changes and foci of necrosis and inflammatory cells (Figure 1 C-E). Hepatic tissue of the group treated by ethanol extract of V2 showed degeneration and vacuolation of the hepatic cytoplasm, with mild fatty changes associated 
Table 4. Glucose tolerance of different experimental groups [Fasting blood glucose and blood glucose after 1/2, 1, 2 and 4 hours from oral glucose administration $(\mathrm{mg} / \mathrm{dL})]$

\begin{tabular}{|c|c|c|c|c|c|}
\hline \multirow[b]{2}{*}{ Groups } & \multicolumn{5}{|c|}{ Blood glucose } \\
\hline & FBS & $\begin{array}{c}1 / 2 \mathrm{~h} \text { from glucose } \\
\text { ingestion }\end{array}$ & $\begin{array}{l}1 \mathrm{~h} \text { from glucose } \\
\text { ingestion }\end{array}$ & $\begin{array}{l}2 \mathrm{~h} \text { from glucose } \\
\text { ingestion }\end{array}$ & $\begin{array}{c}4 \mathrm{~h} \text { from glucose } \\
\text { ingestion }\end{array}$ \\
\hline Normal control & $62.17 \pm 2.10^{\mathrm{a}}$ & $123.33 \pm 13.74^{b}$ & $112^{\mathrm{b}} \pm 8.87$ & $101.83 \pm 4.48^{b}$ & $96.17 \pm 4.16^{c}$ \\
\hline CS control & $67.33 \pm 3.49^{\mathrm{a}}$ & $162.50 \pm 6.05^{\mathrm{a}}$ & $150.67 \pm 2.32^{\mathrm{a}}$ & $139.33 \pm 3.19^{a}$ & $125.17 \pm 4.18^{a}$ \\
\hline Ethanol extract of V1 & $65.17 \pm 1.92^{\mathrm{a}}$ & $119.17 \pm 4.08^{b}$ & $110.83 \pm 4.27^{b}$ & $99.83 \pm 6.96^{b}$ & $89.67 \pm 4.79^{c}$ \\
\hline Ethanol extract of V2 & $62.67 \pm 2.08^{a}$ & $127.83 \pm 7.98^{b}$ & $121.17 \pm 6.35^{b}$ & $116.33 \pm 5.08^{b}$ & $108.17 \pm 3.30^{b}$ \\
\hline
\end{tabular}

Results are expressed as mean $\pm \mathrm{SE}$.

Within the same column, means with the same superscript letter are not significantly different while different letters are significantly different at $P<0.05$.

CS: Control with CVD and steatohepatitis.

Table 5. Plasma lipids, malondialdehyde (MDA) and total antioxidant capacity (TAC) and liver fat of different experimental groups

\begin{tabular}{|c|c|c|c|c|c|c|c|c|}
\hline Groups & $\mathrm{TG}(\mathrm{mg} / \mathrm{dL})$ & $\begin{array}{c}\mathrm{T}-\mathrm{C} \\
(\mathrm{mg} / \mathrm{dL})\end{array}$ & $\begin{array}{l}\text { HDL-C (mg/ } \\
\text { dL) }\end{array}$ & $\begin{array}{c}\text { LDL-C } \\
\text { (mg/dL) }\end{array}$ & T-C/HDL-C & $\begin{array}{c}\mathrm{MDA} \\
(\mathrm{nm} / \mathrm{mL})\end{array}$ & $\begin{array}{c}\text { TAC } \\
(\mathrm{mM} / \mathrm{L})\end{array}$ & $\begin{array}{l}\text { Total liver fat } \\
\text { (g/g liver) }\end{array}$ \\
\hline Normal control & $73.83^{b} \pm 1.19$ & $\begin{array}{c}84.83^{b} \pm \\
1.33\end{array}$ & $\begin{array}{c}40.65^{\mathrm{a}} \pm \\
0.85\end{array}$ & $\begin{array}{l}29.42^{b} \\
\pm 1.69\end{array}$ & $\begin{array}{r}2.09^{b} \\
\pm 0.06\end{array}$ & $\begin{array}{l}9.03^{b} \\
\pm 0.54\end{array}$ & $\begin{array}{l}1.27^{\mathrm{a}} \\
\pm 0.03\end{array}$ & $\begin{array}{l}0.06^{b} \\
\pm 0.01\end{array}$ \\
\hline CS control & $102^{\mathrm{a}} \pm 0.93$ & $\begin{array}{c}149.50^{\mathrm{a}} \pm \\
1.23\end{array}$ & $\begin{array}{c}22.70^{b} \pm \\
0.68\end{array}$ & $\begin{array}{c}106.47^{\mathrm{a}} \\
\pm 1.55\end{array}$ & $\begin{array}{r}6.62^{\mathrm{a}} \\
\pm 0.22\end{array}$ & $\begin{array}{l}18.54^{\mathrm{a}} \\
\pm 1,17\end{array}$ & $\begin{array}{l}0.74^{b} \\
\pm 0.11\end{array}$ & $\begin{array}{l}0.25^{\mathrm{a}} \\
\pm 0.02\end{array}$ \\
\hline $\begin{array}{l}\text { Ethanol extract of } \\
\text { quinoa } 1\end{array}$ & $85^{c} \pm 0.97$ & $\begin{array}{c}100.50^{c} \pm \\
1.41\end{array}$ & $23^{b} \pm 0.97$ & $\begin{array}{c}60.45^{c} \\
1.30\end{array}$ & $\begin{array}{r}4.40^{c} \\
\pm 0.17\end{array}$ & $\begin{array}{l}10.10^{\mathrm{b}} \\
\pm 1.00\end{array}$ & $\begin{array}{l}1.26^{\mathrm{a}} \\
\pm 0.05\end{array}$ & $\begin{array}{l}0.13^{c} \\
\pm 0.01\end{array}$ \\
\hline $\begin{array}{l}\text { Ethanol extract of } \\
\text { hualhuas }\end{array}$ & $78.08^{b c} \pm 4.34$ & $103^{c} \pm 2.78$ & $32^{c} \pm 1.93$ & $\begin{array}{c}55.38^{\mathrm{d}} \pm \\
1.14\end{array}$ & $\begin{array}{l}3.26^{d} \\
\pm 0.13\end{array}$ & $\begin{array}{l}10.32^{\mathrm{b}} \\
\pm 0.45\end{array}$ & $\begin{array}{l}0.97^{b} \\
\pm 0.03\end{array}$ & $\begin{array}{l}0.008^{d} \\
\pm 0.005\end{array}$ \\
\hline
\end{tabular}

Results are expressed as mean $\pm \mathrm{SE}$.

Within the same column, means with the same letters are not significantly different while different letters are significantly different at $P<0.05$.

CS: Control with CVD and steatohepatitis.

TG: Triglycerides, T-C: Total cholesterol, HDL-C: High density lipoprotein cholesterol, LDL-C: Low density lipoprotein cholesterol.

Table 6. Nutritional parameters of different experimental groups

\begin{tabular}{|c|c|c|c|c|c|}
\hline \multirow{2}{*}{ Groups } & \multicolumn{5}{|c|}{ Parameters } \\
\hline & Initial Body weight (g) & Final body weight (g) & Body weight gain (g) & Total food intake (g) & Food Efficiency ratio \\
\hline Normal control & $76.50 \pm 2.47^{a}$ & $171.67 \pm 7.20^{\mathrm{a}}$ & $95.17 \pm 5.92^{\mathrm{a}}$ & $637.67 \pm 6.34^{\mathrm{a}}$ & $0.149 \pm 0.009^{a}$ \\
\hline CS control & $76.83 \pm 2.55^{\mathrm{a}}$ & $178.67 \pm 4.32^{\mathrm{a}}$ & $101.83 \pm 4.92^{\mathrm{a}}$ & $635 \pm 4.08^{\mathrm{a}}$ & $0.160 \pm 0.007^{a}$ \\
\hline Ethanol extract of $\mathrm{V} 1$ & $76.67 \pm 3.63^{a}$ & $118 \pm 4.72^{b}$ & $41.33 \pm 4.04^{c}$ & $541.67 \pm 9.17^{c}$ & $0.076 \pm 0.007^{b c}$ \\
\hline Ethanol extract of $\mathrm{V} 2$ & $76.33 \pm 3.59^{a}$ & $134.50 \pm 5.68^{b}$ & $58.17 \pm 7.15^{b}$ & $569.33 \pm 17.29^{b c}$ & $0.102 \pm 0.011^{b}$ \\
\hline
\end{tabular}

Results are expressed as mean $\pm \mathrm{SE}$.

Within the same column, means with the same superscript letter are not significantly different while different letters are significantly different at $P<0.05$.

CS: Control with CVD and steatohepatitis.

with distorted hepatic sinusoids while other group of cells demonstrated necrobiotic changes with activation of von Kupffer cells (Figure 1F\&G). Table 7 reveals improvement of hepatic changes on treatment with both extracts.

Regarding heart tissue, the heart muscle of the control normal group showed that the main architecture of the heart was within normal limit (Figure 2A). Photomicrograph of longitudinal and cross section of heart muscle of the control group with steatohepatitis, demonstrated diffused fragmentation and necrosis of muscle myofibers, pyknosis of the nuclei, and loss of striation with interstitial edema (Figure 2B-C). Photomicrograph of the cross section of the myocardium of the group treated by ethanol extract of V1, demonstrated cytoplasmic vacuolation and necrobiosis of myofibers associated with pyknosis of the nuclei, loss of striation and interstitial edema (Figure 2DF). Photomicrograph of longitudinal and cross section of myocardium of the group treated by ethanol extract of V2 demonstrated necrosis of the myofibers, associated with pyknosis of the nuclei, loss of striation and fragmentation and interstitial edema, congestion of blood capillaries with extravasation of red blood corpuscle in the interstitial tissue of myofibers (Figure 2G\&H).There was remarkable equal improvement by both extracts with some superiority to $\mathrm{V} 1$ as could be seen from Table 8 . 


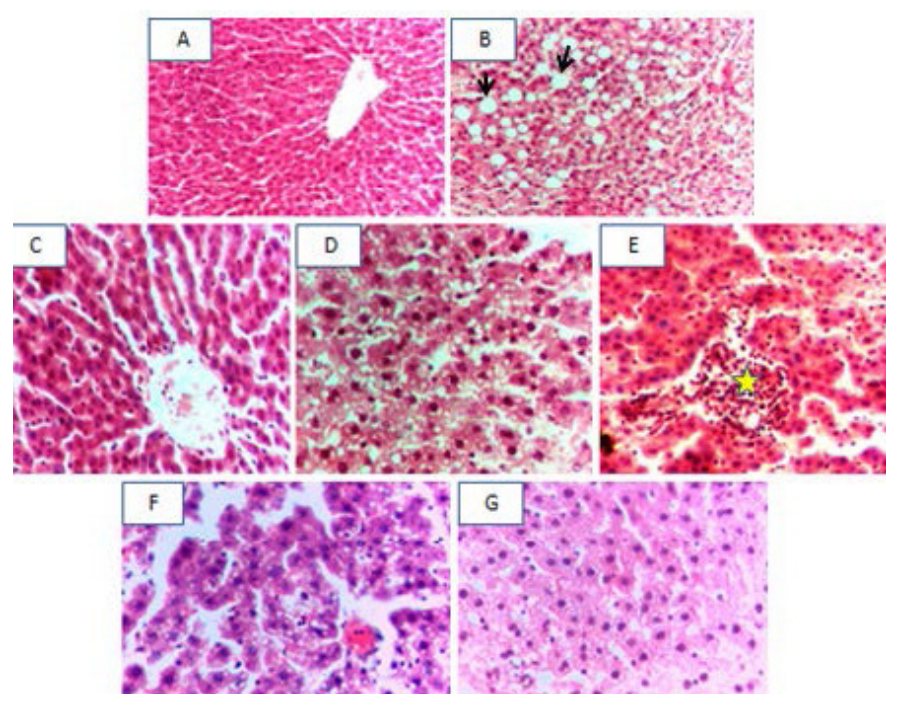

Figure 1. Photomicrograph of hepatic tissue of different experimental groups. A: Hepatic tissue of normal control group (H\&E X200). B: Hepatic tissue of control group with steatohepatitis (H\&E X200); large fat globules are marked by arrows. C-E: Hepatic tissue of the group given ethanol extract of V1 (H\&E. X400); foci of necrosis and inflammatory cells were indicated by star in fig, E. F\&G: Hepatic tissue of the group treated by ethanol extract of V2 (H\&E. X400).
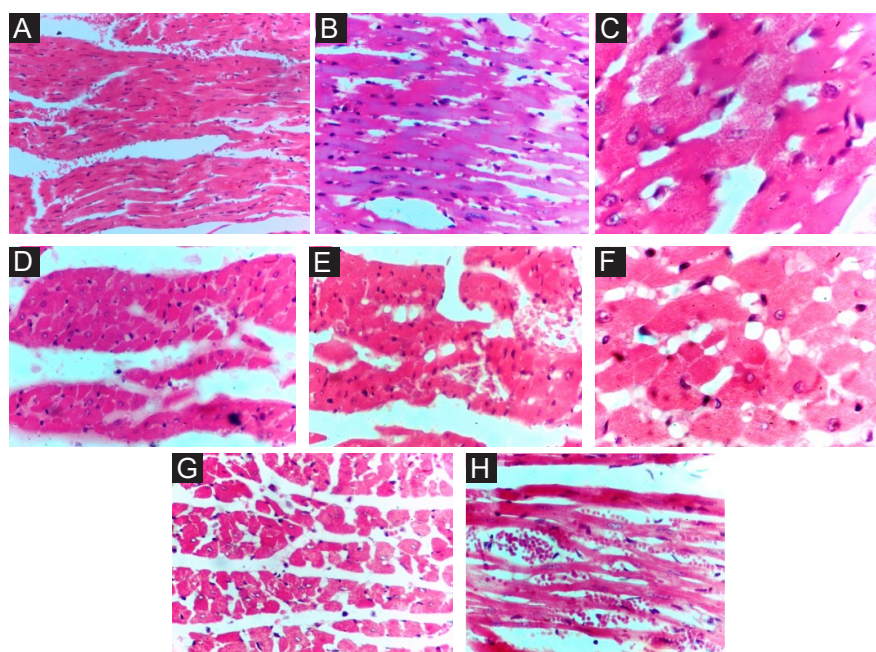

Figure 2. Photomicrograph of heart tissue of different experimental groups. A: Heart muscle of control normal group (H\&E, X200). B: Photomicrograph of longitudinal section of heart muscle of control group with steatohepatitis (H\&E, X400). C: Photomicrograph of cross section of heart muscle of control group with steatohepatitis (H\&E, X1000). D: Photomicrograph of cross section of myocardium of the group treated by ethanol extract of V1 (H\&E, X200). E ( $\mathrm{H} \& \mathrm{E}, \mathrm{X} 200)$ and $\mathbf{F}$ (H\&E, X1000): Photomicrographs of cross section of myocardium of the group given ethanol extract of V1. G: photomicrograph of cross section of myocardium of the group treated by ethanol extract of V2 (H\&E, X200). H: photomicrograph of longitudinal section of myocardium of the group given ethanol extract of V2 (H\&E X400).

\section{Discussion}

Elevated TG, T-C, and LDL-C along with the reduction of HDL-C were reported as risk factors for cardiovascular diseases (CVD), especially on the elevation of $\mathrm{T}-\mathrm{C} /$ HDL-C (25) as could be seen on feeding high fructosehigh fat diet in the present study. These changes in lipid profile on feeding high fructose high fat diet agreed with previous studies $(9,26)$. The improvement in lipid profile, T.C/HDL-C demonstrated in the present study on treatment with quinoa extracts might be attributed to their contents of phenolic compounds. In a previous study, consumption of 50 grams of quinoa on a daily basis for 6 weeks produced mild reduction in TG, T-C, and LDL-C (27). The elevated postprandial blood glucose $(1 / 2,1,2$ and 4 hours) in CS control compared to normal might be related to the induction of metabolic syndrome due to feeding high fructose diet to rats (28). The metabolic syndrome involved fatty liver, hypertriglyceridemia, high abdominal fat, and impaired glucose tolerance due to high insulin resistance (29). On feeding high fat-high sucrose diet, only moderate increase in postprandial blood glucose $(1 / 2 \mathrm{~h})$ was reported (15), pointing to the more potent effect of fructose compared to sucrose. Quinoa ethanol extracts from both varieties improved glucose 
Table 7. The relative degrees of histopathological improvement of liver by different treatments

\begin{tabular}{lccc}
\hline Lesions & $\begin{array}{c}\text { Control normal } \\
\text { (-ve control) }\end{array}$ & $\begin{array}{c}\text { Control with CVD and } \\
\text { steatohepatitis (+ve control) }\end{array}$ & $\begin{array}{c}\text { Ethanol quinoa } \\
\text { extract (V1) }\end{array}$ \\
\hline Cell degeneration & - & +++ & + \\
Cells vacuolation & - & +++ & + \\
Fatty changes & - & +++ & ++ \\
Fatty globules & - & +++ & - \\
Focal necrosis & - & ++ & ++ \\
Distorted hepatic sinusoids & - & +++ & + \\
\hline
\end{tabular}

- Within normal limit, + mild change, ++ moderate changes, +++ severe changes.

Table 8. The relative degrees of histopathological improvement of heart by different treatments

\begin{tabular}{|c|c|c|c|c|}
\hline Lesions & $\begin{array}{l}\text { Normal control } \\
\text { (-ve control) }\end{array}$ & $\begin{array}{c}\text { Control with CVD and } \\
\text { steatohepatitis (+ve control) }\end{array}$ & $\begin{array}{c}\text { Ethanol quinoa } \\
\text { extract (V1) }\end{array}$ & $\begin{array}{c}\text { Ethanol quinoa } \\
\text { extract (V2) }\end{array}$ \\
\hline Degeneration of myofibers & - & +++ & + & ++ \\
\hline Necrosis of myofibers & - & ++++ & ++ & ++ \\
\hline Vacuolation of myocardium & - & + & ++ & + \\
\hline
\end{tabular}

- Within normal limit, + mild change, ++ moderate changes, +++ severe changes, ++++ more severe changes.

tolerance (post prandial glucose; $1 / 2,1,2$, and 4 hours) in the present study. On the other hand, daily consumption of quinoa bread in overweight healthy men for a shortterm modified glucose response, but had minimal effects on other CVD risk biomarkers (30). Quinoa has high potential to improve glucose tolerance $(31,32)$. Quinoa that contains $0.9 \%$ of 20 -hydroxyecdysone, $12 \%$ oil, $20.4 \%$ protein, $1 \%$ total phytoecdysteroids and $2.6 \%$ flavonoid glycosides, produced a significant reduction in fasting blood sugar of hyperglycemic obese mice (33).

Feeding high fructose with high saturated fats induced accumulation of fat in the liver with elevation in oxidative stress and reduction of antioxidant status pointed to induction of fatty liver as reported previously $(9,28)$. The tested extracts produced a significant reduction in MDA referring to their capability to prevent lipid peroxidation. Total antioxidant capacity was only improved on treatment with ethanol extract of quinoa variety 1 . Total liver fat was significantly reduced on both treatments with superiority to V2, referring to inhibition of hepatic liver accumulation by the tested extracts that could be mediated by inhibiting fat synthesis or elevating beta oxidation of fatty acids. Reducing oxidative stress by quinoa extract could lead to anti-inflammatory activity that consequently participates in preventing the progression of fatty liver to steatohepatitis. The antioxidant activity of quinoa demonstrated in the current study might be ascribed to the presence of polyphenols, and flavonoids as reported previously (2). The presence of phenolic compounds in ethanol extract of quinoa represented by different phenolic acids and flavonoids, as could be seen from the results of the present research, supported the abovementioned study.
Previously it was reported that the concentrations of phenolic contents in quinoa seeds were 67.5-102.86 mg $\mathrm{GAE} / 100 \mathrm{~g}$ while the flavonoids ranged from 1.65 to 26.93 mg QE/100 g sample; the yields depend on the extraction condition (34). The present work showed higher level of total phenolic that could be due to the fact that it was determined in the extract, not in the whole seed.

Plant sources rich in phenolic and flavonoids were reported to possess antioxidant activity (35). The beneficial properties of phenolic content are related mainly to its antioxidant activity (7). Antioxidant phenolics could reduce oxidative stress through their free radical scavenging activity, chelation of metal ions, and via working as a reducing agent (36). The DPPH assay is considered a reliable and reproducible in-vitro antioxidant method, among other assays (37). Therefore, the DPPH radical scavenging method could properly reflect the radical scavenging activity of an extract. DPPH scavenging activity of the ethanol extracts of quinoa varieties in the current study showed appreciable antioxidant activity, which was high in V1 compared to V2. This result supported the results of in-vivo study that showed V1 more efficient in elevating TAC than V2. It is worthy of mentioning that the DPPH scavenging activity of the two extracts was correlated to the total phenolic contents of the extracts. In a previous work two varieties; quinoa (Chenopodium quinoa Willd) and kaniwa (Chenopodium pallidicaule Aellen) were shown to contain a high level of phenolic compounds and had high antioxidant activity ( $86 \%$ and $75 \%$, respectively). They were proposed to have an impact on managing type 2 diabetes and associated hypertension through in-vitro study that were ascribed to their content of phenolic compounds (38). 
It was demonstrated that different phenolic acids were identified in quinoa represented by p-hydroxybenzoic acid, vanillic, p-coumaric, and ferulic acid as well as the flavonoids quercetin and kaempferol (34). However, another study (5) reported the presence of caffeic acid, myricetin, and isorhamnetin. In agreement to the aforementioned study (34), p-hydroxybenzoic, p-coumaric, ferulic acids, and kaempferol were identified in the present work in addition of extra 8 compounds as could be seen from the present results.

The superiority of V2 in improving plasma lipid profile and reducing liver fats compared to $\mathrm{V} 1$ and the elevated efficiency of V1 as antioxidants could be seen in both the in-vitro and in-vivo studies, which might be attributed to the different composition of phenolic acid and flavonoids compounds of the two varieties.

The reduction in rat body weight, total food intake, and food efficiency ratio exhibited in the present work on treatment with different quinoa extracts pointed to the anti-obesity property of ethanol extracts of both quinoa varieties.

\section{Conclusion}

Quinoa extracts were capable of inhibiting the progression of steatohepatitis and CVD, along with improving glucose tolerance, and reducing body weight. Therefore they might be beneficial in patients suffering from steatohepatitis, CVD, abnormal glucose tolerance, and overweight.

\section{Acknowledgements}

The work was completely carried out in National Research Centre, Egypt.

\section{Authors' contributions}

ASY designed the study, wrote the manuscript with interpretation of the results. HTE, RAA, ETE, EMF and $\mathrm{BAB}$ implemented the practical part. All authors read and approved the final version and agreed to publish it.

\section{Conflict of interests}

None to be declared.

\section{Ethical considerations}

The animal experiment was carried out according to the Medical Research Ethics Committee, National Research Centre, Cairo, Egypt (Agreement for project No.11030126) and followed the recommendations of the National Institute of Health Guide for Care and Use of Laboratory animals (Publication No-85-23, revised 1985).

\section{Funding/Support}

This research was funded by National Research Centre, Egypt. Project No: 11030126.

\section{References}

1. Bhargava A, Shukla S, Ohri D. Chenopodium quinoa-an
Indian perspective. Ind Crops Prod. 2006;23(1):73-87. doi: https://doi.org/10.1016/j.indcrop.2005.04.002.

2. Abugoch James LE. Quinoa (Chenopodium quinoa Willd.): composition, chemistry, nutritional, and functional properties. Adv Food Nutr Res. 2009;58:1-31. doi: 10.1016/ s1043-4526(09)58001-1.

3. Alvarez-Jubete L, Wijngaard H, Arendt EK, Gallagher E. Polyphenol composition and in vitro antioxidant activity of amaranth, quinoa buckwheat and wheat as affected by sprouting and baking. Food Chem. 2010;119(2):770-8. doi: 10.1016/j.foodchem.2009.07.032.

4. Hirose Y, Fujita T, Ishii T, Ueno N. Antioxidative properties and flavonoid composition of Chenopodium quinoa seeds cultivated in Japan. Food Chem. 2010;119(4):1300-6. doi: 10.1016/j.foodchem.2009.09.008.

5. Repo-Carrasco-Valencia R, Hellström JK, Pihlava J-M, Mattila PH. Flavonoids and other phenolic compounds in Andean indigenous grains: Quinoa (Chenopodium quinoa), kañiwa (Chenopodium pallidicaule) and kiwicha (Amaranthus caudatus). Food Chem. 2010;120(1):128-33. doi: $\quad 10.1016 /$ j.foodchem.2009.09.087.

6. Ammar NM, Al-Okbi SY. Effect of four flavonoids on blood glucose of rats. Arch Pharm Res. 1988;11(2):166-8. doi: $10.1007 / \mathrm{bf} 02857723$.

7. Rice-Evans C, Miller N, Paganga G. Antioxidant properties of phenolic compounds. Trends Plant Sci. 1997;2(4):152-9. doi: 10.1016/s1360-1385(97)01018-2.

8. Al-Okbi SY, Mohamed DA, Hamed TE, Edris AE. Potential protective effect of Nigella sativa crude oils towards fatty liver in rats. Eur J Lipid Sci Technol. 2013;115(7):774-82. doi: 10.1002/ejlt.201200256.

9. Al-Okbi SY, El-Qousy SM, El-Ghlban S, Moawad HF. Role of borage seed oil and fish oil with or without turmeric and alpha- tocopherol in prevention of cardiovascular disease and fatty liver in rats. J Oleo Sci. 2018;67(12):1551-62. doi: 10.5650/jos.ess18064.

10. Singleton VL, Rossi JA. Colorimetry of total phenolics with phosphomolybdic-phosphotungstic acid reagents. Am J Enol Vitic. 1965;16(3):144-58.

11. Kim KH, Tsao R, Yang R, Cui SW. Phenolic acid profiles and antioxidant activities of wheat bran extracts and the effect of hydrolysis conditions. Food Chem. 2006;95(3):466-73. doi: 10.1016/j.foodchem.2005.01.032.

12. Hwang ES, Thi ND. Effects of extraction and processing methods on antioxidant compound contents and radical scavenging activities of laver (Porphyra tenera). Prev Nutr Food Sci. 2014;19(1):40-8. doi: 10.3746/pnf.2014.19.1.040.

13. Oktay M, Gülçin İ, Küfrevioğlu Öİ. Determination of in vitro antioxidant activity of fennel (Foeniculum vulgare) seed extracts. LWT - Food Sci Technol. 2003;36(2):263-71. doi: 10.1016/S0023-6438(02)00226-8.

14. Kawasaki T, Igarashi K, Koeda T, Sugimoto K, Nakagawa $\mathrm{K}$, Hayashi S, et al. Rats fed fructose-enriched diets have characteristics of nonalcoholic hepatic steatosis. J Nutr. 2009;139(11):2067-71. doi: 10.3945/jn.109.105858.

15. Al-Okbi SY, Hussein AMS, Elbakry HFH, Fouda KA, Mahmoud KF, Hassan ME. Health benefits of fennel, rosemary volatile oils and their nano-forms in dyslipidemic rat model. Pak J Biol Sci. 2018;21(7):348-58. doi: 10.3923/ pjbs.2018.348.358. 
16. Watson D. A simple method for the determination of serum cholesterol. Clin Chim Acta. 1960;5:637-43. doi: 10.1016/0009-8981(60)90004-8.

17. Burstein M, Scholnick HR, Morfin R. Rapid method for the isolation of lipoproteins from human serum by precipitation with polyanions. J Lipid Res. 1970;11(6):583-95.

18. Megraw RE, Dunn DE, Biggs HG. Manual and continuousflow colorimetry of triacylglycerols by a fully enzymic method. Clin Chem. 1979;25(2):273-8.

19. Friedewald WT, Levy RI, Fredrickson DS. Estimation of the concentration of low-density lipoprotein cholesterol in plasma, without use of the preparative ultracentrifuge. Clin Chem. 1972;18(6):499-502.

20. Satoh K. Serum lipid peroxide in cerebrovascular disorders determined by a new colorimetric method. Clin Chim Acta. 1978;90(1):37-43. doi: 10.1016/0009-8981(78)90081-5.

21. Koracevic D, Koracevic G, Djordjevic V, Andrejevic S, Cosic V. Method for the measurement of antioxidant activity in human fluids. J Clin Pathol. 2001;54(5):356-61. doi: $10.1136 /$ jcp.54.5.356.

22. Folch J, Lees M, Sloane Stanley GH. A simple method for the isolation and purification of total lipides from animal tissues. J Biol Chem. 1957;226(1):497-509.

23. Cequier-Sánchez E, Rodríguez C, Ravelo AG, Zárate R. Dichloromethane as a solvent for lipid extraction and assessment of lipid classes and fatty acids from samples of different natures. J Agric Food Chem. 2008;56(12):4297303. doi: 10.1021/jf073471e.

24. Bancroft JD, Layton C. The Hematoxylins and Eosin. In: Suvarna SK, Layton C, Bancroft JD, eds. Bancroft's Theory and Practice of Histological Techniques. Vol. 8. Elsevier; 2019. p. 126-38.

25. Seo HS, Choi MH. Cholesterol homeostasis in cardiovascular disease and recent advances in measuring cholesterol signatures. J Steroid Biochem Mol Biol. 2015;153:72-9. doi: 10.1016/j.jsbmb.2015.04.014.

26. Al-Okbi SY, Mohamed DA, Hamed TE, Esmail RSH. Rice bran oil and pumpkin seed oil alleviate oxidative injury and fatty liver in rats fed high fructose diet. Pol J Food Nutr Sci. 2014;64(2):127-33. doi: 10.2478/pjfns-2013-0002.

27. Zevallos VF, Herencia LI, Chang F, Donnelly S, Ellis HJ, Ciclitira PJ. Gastrointestinal effects of eating quinoa (Chenopodium quinoa Willd.) in celiac patients. Am J Gastroenterol. 2014;109(2):270-8. doi: 10.1038/ ajg.2013.431

28. Al-Okbi SY, Mohamed DA, Hamed TE, Edris AE. Protective effect of clove oil and eugenol microemulsions on fatty liver and dyslipidemia as components of metabolic syndrome. J Med Food. 2014;17(7):764-71. doi: 10.1089/jmf.2013.0033.

29. Al-Okbi SY. Role of nutraceuticals in prevention of nonalcoholic fatty liver. In: Goyal MR, Chauhan DN, eds Plantand Marine- Based Phytochemicals for Human Health: Attributes, Potential, and Use. Apple Academic Press, Taylor and Francis; 2018. p.131-49.

30. Li L, Lietz G, Bal W, Watson A, Morfey B, Seal C. Effects of quinoa (Chenopodium quinoa Willd.) consumption on markers of CVD risk. Nutrients. 2018;10(6). doi: 10.3390/ nu10060777.

31. Mithila MV, Khanum F. Effectual comparison of quinoa and amaranth supplemented diets in controlling appetite; a biochemical study in rats. J Food Sci Technol. 2015;52(10):6735-41. doi: 10.1007/s13197-014-1691-1.

32. Gabrial SG, Shakib MR, Gabrial GN. Effect of pseudocerealbased breakfast meals on the first and second meal glucose tolerance in healthy and diabetic subjects. Open Access Maced J Med Sci. 2016;4(4):565-73. doi: 10.3889/ oamjms.2016.115.

33. Graf BL, Poulev A, Kuhn P, Grace MH, Lila MA, Raskin I. Quinoa seeds leach phytoecdysteroids and other compounds with anti-diabetic properties. Food Chem. 2014;163:178-85. doi: 10.1016/j.foodchem.2014.04.088.

34. Carciochi RA, Manrique GD, Dimitrov K. Optimization of antioxidant phenolic compounds extraction from quinoa (Chenopodium quinoa) seeds. J Food Sci Technol. 2015;52(7):4396-404. doi: 10.1007/s13197-014-1514-4.

35. Guo H, Saravanakumar K, Wang M-H. Total phenolic, flavonoid contents and free radical scavenging capacity of extracts from tubers of Stachys affinis. Biocatal Agric Biotechnol. 2018;15:235-9. doi: 10.1016/j.bcab.2018.06.009.

36. Madhujith T, Shahidi F. Optimization of the extraction of antioxidative constituents of six barley cultivars and their antioxidant properties. J Agric Food Chem. 2006;54(21):8048-57. doi: 10.1021/jf061558e.

37. Koleva, II, van Beek TA, Linssen JP, de Groot A, Evstatieva LN. Screening of plant extracts for antioxidant activity: a comparative study on three testing methods. Phytochem Anal. 2002;13(1):8-17. doi: 10.1002/pca.611.

38. Ranilla LG, Apostolidis E, Genovese MI, Lajolo FM, Shetty K. Evaluation of indigenous grains from the Peruvian Andean region for antidiabetes and antihypertension potential using in vitro methods. J Med Food. 2009;12(4):704-13. doi: 10.1089/jmf.2008.0122. 